Abstract P183 Table 1

Table 1: Patient characteristics of 95 screened patients

\begin{tabular}{|c|c|c|c|c|}
\hline & \multicolumn{4}{|c|}{ Eligible by enrolment criteria $\left(\mathrm{FEV}_{1} / \mathrm{FVC}>0.7, \mathrm{FEV}_{1}>80 \%\right.$ predicted, without asthma) } \\
\hline & \multirow[b]{2}{*}{$\begin{array}{l}\text { Eligible patients } \\
(n=55)\end{array}$} & \multicolumn{3}{|c|}{ Not eligible $(n=40)$} \\
\hline & & $\begin{array}{l}\text { Non-obstructive } \\
\text { ratio }(n=27)\end{array}$ & $\begin{array}{l}\text { Obstructive ratio \& } \\
\mathrm{FEV}_{1}>80 \%(\mathrm{n}=10)\end{array}$ & $\begin{array}{l}\text { History of asthma } \\
(n=3)\end{array}$ \\
\hline Age, years (mean[SD]) & $69(10)$ & $68(10)$ & $72(14)$ & $68(1)$ \\
\hline Gender, Male (patients [\%]) & $42(76)$ & $16(59)$ & $5(50)$ & $2(67)$ \\
\hline History of smoking (patients [\%]) & $55(100)$ & $27(100)$ & $10(100)$ & $2(67)$ \\
\hline Pack-year history (mean[SD]) & $45(37)$ & $31(25)$ & $36(16)$ & $2(3)$ \\
\hline $\begin{array}{l}\text { Exacerbation frequency } \\
\text { (mean[SD]) }\end{array}$ & $1.8(2.3)$ & $1.8(2.4)$ & $1(1.1)$ & $1.7(1.5)$ \\
\hline \multicolumn{5}{|l|}{ Spirometry (mean[SD]) } \\
\hline FEV1 & $1.41(0.46)$ & $2.30(0.52)$ & $2.28(0.55)$ & $1.73(0.72)$ \\
\hline FVC & $2.70(0.84)$ & $3.06(0.70)$ & $3.68(0.78)$ & $2.86(0.82)$ \\
\hline $\mathrm{FEV}_{1}(\%$ predicted $)$ & $54(13)$ & $86(19)$ & $89(4)$ & $60(13)$ \\
\hline $\mathrm{FEV}_{1} / \mathrm{FVC}$ ratio & $0.52(0.09)$ & $0.75(0.05)$ & $0.62(0.06)$ & $0.60(0.10)$ \\
\hline
\end{tabular}

[5\%] were enrolled in other research, and 37 [21\%] were unsuitable for other reasons). 8 appointments were pending with screening data available for 95 patients (Table 1). 40 patients (42\%) did not satisfy the spirometric inclusion criteria; 27 did not show airflow obstruction, 10 had mild COPD, and 3 had asthma. Approximately 25 contact letters and up to $£ 260$ were therefore required per eligible patient identified.

Conclusion A high proportion of patients on primary care databases fail to meet spirometric criteria for COPD trials and the screening failure rate via this recruitment pathway is much higher than previously reported. A large number of initial contacts are required for each patient identified. COPD patients are increasingly managed in primary care and these findings therefore have implications for planning future studies.

1. Albert, NEJM, 2011; 365(8):p689-98.

2. Jones, Respir Res, 2008; 9:p62.

\section{P184 APPLYING THE GOLD 2011 CLASSIFICATION TO A REAL- WORLD COPD POPULATION IN GERMANY}

doi:10.1136/thoraxjnl-2012-202678.245

${ }^{1} \mathrm{C}$ Vogelmeier, ${ }^{2 \mathrm{M}}$ Small, ${ }^{2} \mathrm{~S}$ Broomfield, ${ }^{3} \mathrm{~J}$ Vestbo. 'Marburg University Hospital, Marburg, Germany; ${ }^{2}$ Adelphi Real World, Macclesfield, UK; ${ }^{3}$ Respiratory Research Group, Manchester, UK

Objectives The GOLD 2011 Strategy now recommends assessment based on exacerbation history and symptoms in addition to airflow limitation. Our goal was to better understand this classification system by analysing the distribution of patients across the 4 groups, their treatment and comorbidities in a real-world population.

Methods GOLD 2011 criteria were applied to a German COPD population sampled from the Adelphi Respiratory Disease Specific Programme undertaken in 2011. Patients were recruited from consulting primary and specialist physicians. Chi-squared tests were performed.

Results 507 patients had a FEV value and/or exacerbation history and COPD Assessment Test (CAT) score. 10.5\% of patients scored 0-9 using CAT, resulting in an uneven distribution of patients in groups A-D, 7.7, 49.9, 2.8 and 39.6\% respectively. Using mMRC the distribution of patients in groups A-D was 35.1, 20.9, 19.1, and $24.9 \%$. Inhaled corticosteroid (ICS) therapy was prescribed to 51.3 , 57.9 and $42.7 \%$ of group A, B and D patients, respectively. Cardiovascular disease $(51.3,68.0,75.2 \%[p=0.02])$, diabetes $(6.5,17.8$, $18.9 \%[p=0.20])$ and obesity $(0,12.6,16.8 \%[p=0.04])$ increased across groups $\mathrm{A}, \mathrm{B}$ and $\mathrm{D}$ respectively. Due to low numbers, group $\mathrm{C}$ was excluded from the comparison analysis.

Conclusion $2.8 \%$ of patients qualified as high risk/low symptoms suggesting this patient type is rare based on a CAT evaluation, using mMRC this proportion was $19.1 \%$. An education gap exists regarding the appropriate use of ICS given the high proportion of treated low risk patients. CV and metabolic comorbidities are more prevalent with increasing risk/symptoms so a holistic approach may be necessary, especially for group D patients.

\section{P185 QUANTIFICATION AND TREATMENT PATTERNS OF REAL-WORLD PATIENTS CLASSIFIED BY THE GOLD 2011 STRATEGY}

doi:10.1136/thoraxjnl-2012-202678.246

M Small, S Broomfield, V Higgins. Adelphi Real World, Macclesfield, UK

Objectives The Global Initiative for Chronic Obstructive Lung Disease (GOLD) 2011 Strategy classifies COPD patients into 4 categories (A: low risk, less symptoms; B: low risk, more symptoms; C: high risk, less symptoms; D: high risk, more symptoms) based on risk $\left(\mathrm{FEV}_{1} \geq\right.$ or $<50 \%$ predicted and/or exacerbation history $<$ or $\geq 2$ per year) and symptoms (COPD Assessment test [CAT] score $<$ or $\geq 10$ or modified Medical Research Council [mMRC] dyspnoea scale $<$ or $\geq 2$ ). We examined the proportion of patients in each category when evaluated by CAT or mMRC, and corresponding pharmacological treatment (CAT classification).

Methods GOLD 2011 criteria were applied to a real-world international COPD population sampled from the Adelphi Respiratory Disease Specific. Programme undertaken between June 2011 and September 2011. Physicians and patients completed matched questionnaires.

Results 2392 patients completed a questionnaire, of which 1508 with all 4 GOLD classification parameters were analyzed. The 